\title{
Photocatalytic Degradation of Single and Binary Mixture of Brilliant Green and Rhodamine B Dyes by Zinc Sulfide Quantum Dots
}

\author{
Peter A. Ajibade *(1) and Abimbola E. Oluwalana
}

check for updates

Citation: Ajibade, P.A.; Oluwalana, A.E. Photocatalytic Degradation of Single and Binary Mixture of Brilliant Green and Rhodamine B Dyes by Zinc Sulfide Quantum Dots. Molecules 2021, 26, 7686. https:// doi.org/10.3390/molecules26247686

Academic Editor: Jonathan Albo

Received: 14 November 2021 Accepted: 13 December 2021 Published: 19 December 2021

Publisher's Note: MDPI stays neutra with regard to jurisdictional claims in published maps and institutional affiliations.

Copyright: (c) 2021 by the authors. Licensee MDPI, Basel, Switzerland. This article is an open access article distributed under the terms and conditions of the Creative Commons Attribution (CC BY) license (https:/ / creativecommons.org/licenses/by/ $4.0 /)$.
School of Chemistry and Physics, University of KwaZulu-Natal, Private Bag, Scottsville, Pietermaritzburg 3209, South Africa; 217075609@stu.ukzn.ac.za

* Correspondence: ajibadep@ukzn.ac.za

Abstract: We present the preparation of octadecylamine-capped ZnS quantum dots from bis(morpholi nyldithiocarbamato) $\mathrm{Zn}$ (II) complex. The complex was thermolyzed at $130{ }^{\circ} \mathrm{C}$ in octadecylamine at different times, to study the effect of reaction time on the morphological and photocatalytic properties of the $\mathrm{ZnS}$ quantum dots. Powder X-ray diffraction patterns confirmed a hexagonal wurtzite crystalline phase of ZnS, while HRTEM images showed particle sizes of about 1-3 nm, and energy band gaps of $3.68 \mathrm{eV}$ (ZnS-1), $3.87 \mathrm{eV}$ (ZnS-2), and $4.16 \mathrm{eV}$ (ZnS-3) were obtained from the Tauc plot for the $\mathrm{ZnS}$ nanoparticles. The as-prepared $\mathrm{ZnS}$ were used as photocatalysts for the degradation of brilliant green, rhodamine B, and binary dye consisting of a mixture of brilliant green-rhodamine $\mathrm{B}$. The highest photocatalytic degradation efficiency of $94 \%$ was obtained from ZnS-3 with low photoluminescence intensity. The effect of catalytic dosage and $\mathrm{pH}$ of the dyes solution on the photocatalytic process shows that $\mathrm{pH} 8$ is optimal for the degradation of brilliant green, while $\mathrm{pH} 6.5$ is the best for photocatalytic degradation of rhodamine B. The degradation of the binary dyes followed the same trends. The effect of catalytic dosage shows that $1 \mathrm{mg} \mathrm{mL}^{-1}$ of the $\mathrm{ZnS}$ nano-photocatalyst is the optimum dosage for the degradation of organic dyes. Reusability studies show that the $\mathrm{ZnS}$ quantum dots can be reused five times without a significant reduction in degradation efficiency.

Keywords: ZnS; quantum dots; morphologies; photodegradation; brilliant green; rhodamine B; binary dye

\section{Introduction}

Rapid industrialization over decades has resulted in the release of organic contaminants into water bodies [1,2]. About 70,000 tons of industrial effluents produced annually are nondegradable organic compounds, and nearly $80 \%$ of the dyes among these organic contaminants are azo dyes $[3,4]$. The chemical structures of these dyes consist of aromatic rings that cannot be easily broken or biodegraded; they are also highly toxic, with mutagenic effects on aquatic life and humans [5,6]. An advanced oxidation process is one of the methods being used for wastewater treatment, especially the removal of organic contaminants [7-9]. An advanced oxidation process such as photocatalysis is based on the photogeneration of electron-hole pairs through a redox reaction at the semiconductor interface, to generate reactive species that interact with organic pollutants $[10,11]$. Interest in the use of semiconductor nanoparticles as photocatalysts for the degradation of organic dyes and subsequent removal from the environment is ascribed to the process being economical, without generating secondary pollutants [12-14]. $\mathrm{TiO}_{2}$ and $\mathrm{ZnO}$ are among the most commonly used semiconductors photocatalysts, but their applications are hindered by slow reaction kinetics due to the fast recombination of photogenerated electron-hole pairs [15]. Thus, there is a need to develop low-dimensional semiconductor materials with unique physiochemical, optical, and electronic properties [16-20]. Zinc-based nanomateri- 
als are environmentally friendly at low concentration, and it is one of the most abundant trace metals in the human body [21]. Hence, zinc sulfide is among the semiconductor nanoparticles that can be used as a photocatalyst due to its high surface-area-to-volume ratio [22], which could enhance photon absorption at the nanointerface.

Xiao et al. [23] reported biofabrication of zinc sulfide nanoparticles, using the bacterium Shewanella oneidenis to partially degrade rhodamine $\mathrm{B}$ to $\mathrm{N}^{\prime}, \mathrm{N}^{\prime}, \mathrm{N}^{\prime}, \mathrm{N}^{\prime}$-tetraethylrhodamine after $3 \mathrm{~h}$. Osuntokun et al. [24] tuned the morphology and optical properties of $\mathrm{ZnS}$ quantum dots prepared from the adduct of $\mathrm{Zn}$ (II) complexes. The $\mathrm{ZnS}$ quantum dots degraded ca. $75 \%$ methylene blue after $6 \mathrm{~h}$. ZnS quantum dots prepared via co-precipitation-method photos catalytically degraded $80 \%$ of brilliant green dye after 80 min under solar-light irradiation [25]. Porous tube-like ZnS exhibited excellent degradation activity against $\mathrm{Cr}(\mathrm{VI})$ and reactive red $\mathrm{X}-3 \mathrm{~B}$ under UV light with good reusability and stability after three cycles [26]. Biogenic $\mathrm{ZnS}$ quantum dots photodegraded $88 \%$ of organic dyes under sunlight after $8 \mathrm{~h}$ [27]. However, most of the reports on the use of $\mathrm{ZnS}$ quantum dots as photocatalysts showed that they suffer from low photodegradation efficiency [28-30]. Hence, the search for highly efficient $\mathrm{ZnS}$ quantum photocatalysts is a continuing effort. The size-dependent properties of nanomaterials depend most often on the synthetic approaches used for the preparation of the chalcogenide's nanoparticles. Among synthetic techniques used for the preparation of metal sulfide nanoparticles, the use of single source precursors is an effective synthetic approach for the preparation of metal sulfide nanoparticles [31-33]. In this paper, bis(morpholinyldithiocarbamato)Zn(II) complex was used as a single-source precursor to prepare $\mathrm{ZnS}$ quantum dots. The precursor was thermolyzed in octadecylamine at $30 \mathrm{~min}, 1 \mathrm{~h}$, and $2 \mathrm{~h}$ to evaluate the effect of thermolysis time on the optical, morphological, and photocatalytic properties of the as-prepared ZnS quantum dots. The photocatalytic potential of the as-prepared $\mathrm{ZnS}$ quantum dots was evaluated using brilliant green, rhodamine B, and binary dye mixture of brilliant green and rhodamine $\mathrm{B}$. We also investigated the effect of the $\mathrm{ZnS}$ quantum dots' catalytic dosage, scavengers, and $\mathrm{pH}$ on the photocatalytic degradation efficiency of the organic dyes by the as-prepared ZnS quantum dots.

\section{Results and Discussions}

\subsection{Structural and Morphological Studies of ZnS Quantum Dots}

Powder X-ray diffraction patterns (Figure S1-Supplementary Materials) of ZnS-1 peaks at $22.87^{\circ}, 24.41^{\circ}, 27.76^{\circ}, 33.15^{\circ}, 42.87^{\circ}, 47.40^{\circ}, 52.46^{\circ}, 56.05^{\circ}$, and $66.59^{\circ}$ are indexed to the (100), (002), (101), (200), (102), (110), (103), (113), and (202) diffraction planes of the hexagonal wurtzite $\mathrm{ZnS}$ crystalline phase, while in the diffraction patterns of ZnS-2 and ZnS-3, peaks at $23^{\circ}, 27.73^{\circ}, 23.36^{\circ}, 43.05^{\circ}, 46.74^{\circ}, 51.87^{\circ}, 55.70^{\circ}$, and $66.15^{\circ}$ correspond to the (100), (101), (200), (102), (110), (103), (113), and (202) planes of the ZnS hexagonal wurtzite phase [JCPDS card no: 39-1363, a= 3.820, $\mathrm{c}=24.960 \AA$ ] [34,35]. The broad diffraction peaks at $23^{\circ}, 28^{\circ}$, and $33^{\circ}$ affirmed that the particle sizes of the as-prepared ZnS are zero-dimensional in the quantum dots' nanometer range [11,36]. The XRD patterns show that diffraction peaks become sharper as thermolysis time increases [37].

HRTEM micrographs of the as-prepared ZnS quantum dots show that ZnS-1 (Figure 1a) prepared at $30 \mathrm{~min}$ is spherical in shape with a particle size of $1.3 \mathrm{~nm}$, while ZnS-2 (Figure $1 \mathrm{~d}$ ), prepared at $1 \mathrm{~h}$ have particle sizes in the range of $1.08-3.42 \mathrm{~nm}$, and the particle sizes of ZnS-3 (Figure 1g), prepared at $2 \mathrm{~h}$ are in the range of $0.80-2.88 \mathrm{~nm}$. The particle size distributions of the as-prepared $\mathrm{ZnS}$ quantum dots are presented in Figure S2. The interplanar spacing of the ZnS quantum dots' (Figure 1b,e,h) lattice fringe of $0.22 \mathrm{~nm}$ corresponds to the (101) hexagonal plane [38]. The SAED patterns of the ZnS-1 quantum $\operatorname{dot}$ (Figure 1c) confirmed that the as-prepared ZnS are highly crystalline in nature [34]. The SAED patterns of ZnS-2 (Figure 1f) and ZnS-3 (Figure 1i) consist of three blurred circular ring patterns, which indicate the presence of an amorphous layer that could be ascribed to the deposition of some capping agent on the surface during microscopic analyses. The SEM images (Figure S3) show cubic-like surface morphology for ZnS-1 and ZnS-3, while ZnS-2 
has a rough surface morphology. The presence of zinc and sulfur in a semi-quantitative 1:1 ratio in the EDX spectra (Figure S4) confirms the existence of zinc sulfide quantum dots. The spectra also show carbon and oxygen ascribed to the octadecylamine capping agents. The presence of gold in the spectra is due to the material used for coating the samples to run the SEM-EDX analysis.


Figure 1. HRTEM images of ZnS-1 (a), ZnS-2 (d) and ZnS-3 (g); lattice fringes, (b,e,h) and SAED patterns, (c,f,i) for zinc sulfide quantum dots.

FTIR spectra of the ZnS quantum dots (Figure 2) confirm the interactions of the octadecylamine-capping agent with $\mathrm{ZnS}$. The $\mathrm{C}-\mathrm{C}$ stretching vibrations of the capping agent appeared at $2853 \mathrm{~cm}^{-1}$ and $2907 \mathrm{~cm}^{-1}$, while the bands at $1367 \mathrm{~cm}^{-1}$ and $1466 \mathrm{~cm}^{-1}$ are attributed to $\mathrm{C}-\mathrm{H}$ stretching vibrational modes [39]. ZnS stretching vibrations were observed at $1636 \mathrm{~cm}^{-1}$ and $1089 \mathrm{~cm}^{-1}$ [40-42], while the N-H absorption band was observed at $3330 \mathrm{~cm}^{-1}$, which confirms octadecylamine (ODA) as a capping agent on the surface of the $\mathrm{ZnS}$ quantum dots. The absence of $\mathrm{C}=\mathrm{O}$ stretching frequency at $1700 \mathrm{~cm}^{-1}$ confirms that oleic acid (OA) is not present on the surface of the $\mathrm{ZnS}$ as a capping agent [43,44]. 


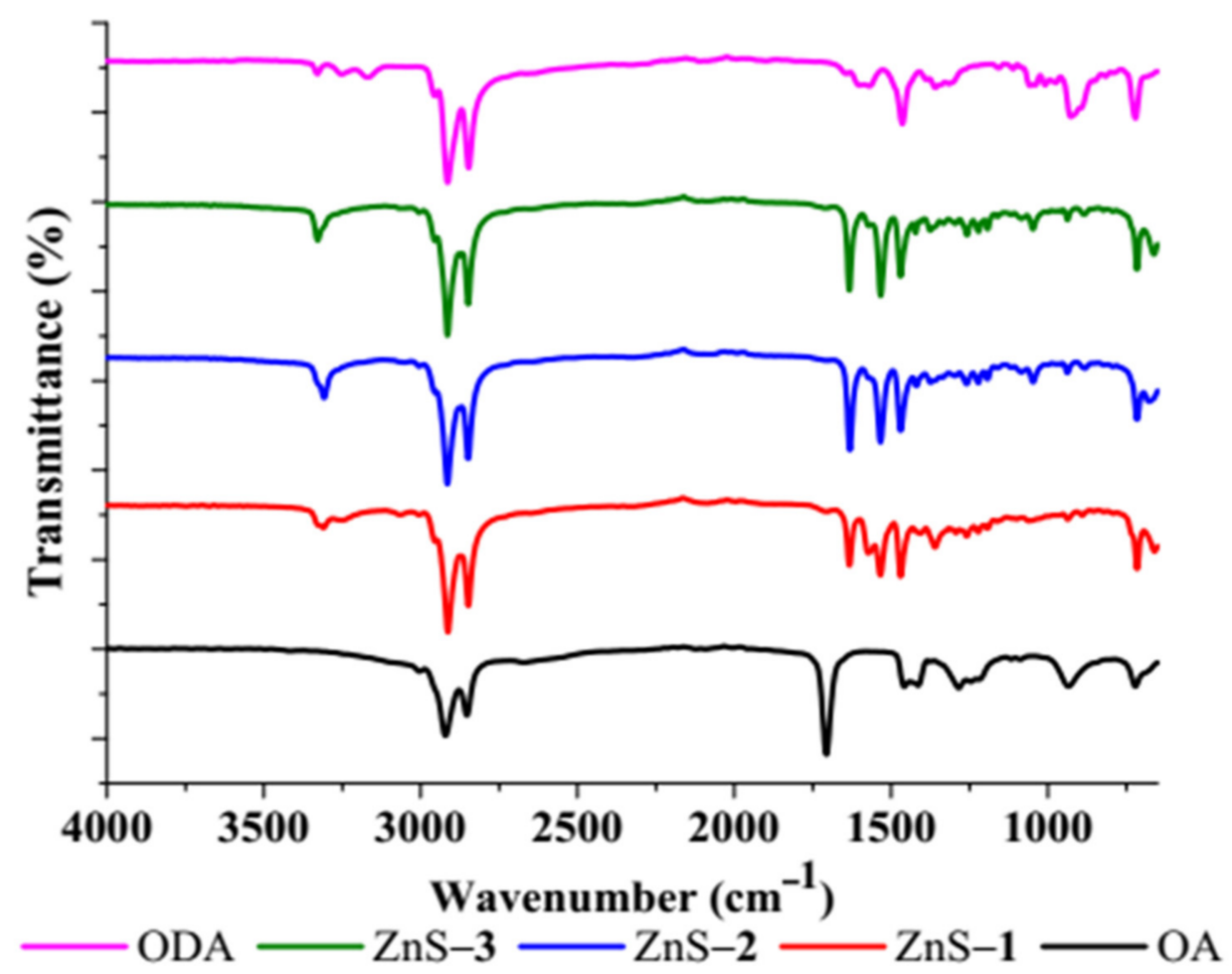

Figure 2. FTIR spectra of ZnS quantum dots.

\subsection{Optical Studies of ZnS Quantum Dots}

Absorption spectra of the as-prepared $\mathrm{ZnS}$ quantum dots (Figure 3a) showed that absorption band edges of ZnS-1 appeared at $303 \mathrm{~nm}$, which were red-shifted in comparison to bulk ZnS (345 nm), while ZnS-2 appeared at $358 \mathrm{~nm}$, and ZnS-3 appeared at $391 \mathrm{~nm}$, which were blue-shifted; this could be ascribed to quantum confinement effect [45]. The optical band gaps estimated from Tauc plots (Figure 3b) were $4.09 \mathrm{eV}$ for ZnS-1, $3.46 \mathrm{eV}$ for ZnS-2, and 3.17 eV for ZnS-3, respectively. The energy band gap of ZnS-2 and ZnS-3 is lower than the band gap of bulk $\mathrm{ZnS}(3.63 \mathrm{eV})$, while that of $\mathrm{ZnS}-\mathbf{1}$ is higher, which could be ascribed to quantum confinement effect. The photoluminescence spectra of the $\mathrm{ZnS}$ quantum dots measured at $350 \mathrm{~nm}$ excitation wavelength at room temperature (Figure 3c) showed narrow emission bands in the range of $480-540 \mathrm{~nm}$. The emission spectra are dependent on an interfacial process, which occurs between the particle's boundary and the surrounding medium [46,47]. The ZnS quantum dots emission maxima appeared at $517 \mathrm{~nm}$ for ZnS-1 and ZnS-2, while that of ZnS-3 appeared at $499 \mathrm{~nm}$. These emission bands are associated with zinc vacancies and interstitial zinc atoms [12,40]. The increase in the emission spectra intensity resulted in the recombination of photogenerated electrons and holes [48,49]. ZnS-1 and ZnS-2, with higher intensity, indicate a high recombination of photo-induced charge carriers, which could lead to low photocatalytic activity, whereas ZnS-3, with low intensity, is expected to have better separation efficiency, which could enhance its photocatalytic activity. The differences observed in the emission peaks of the $\mathrm{ZnS}$ quantum dots are similar to what has been reported previously [12,24]. 

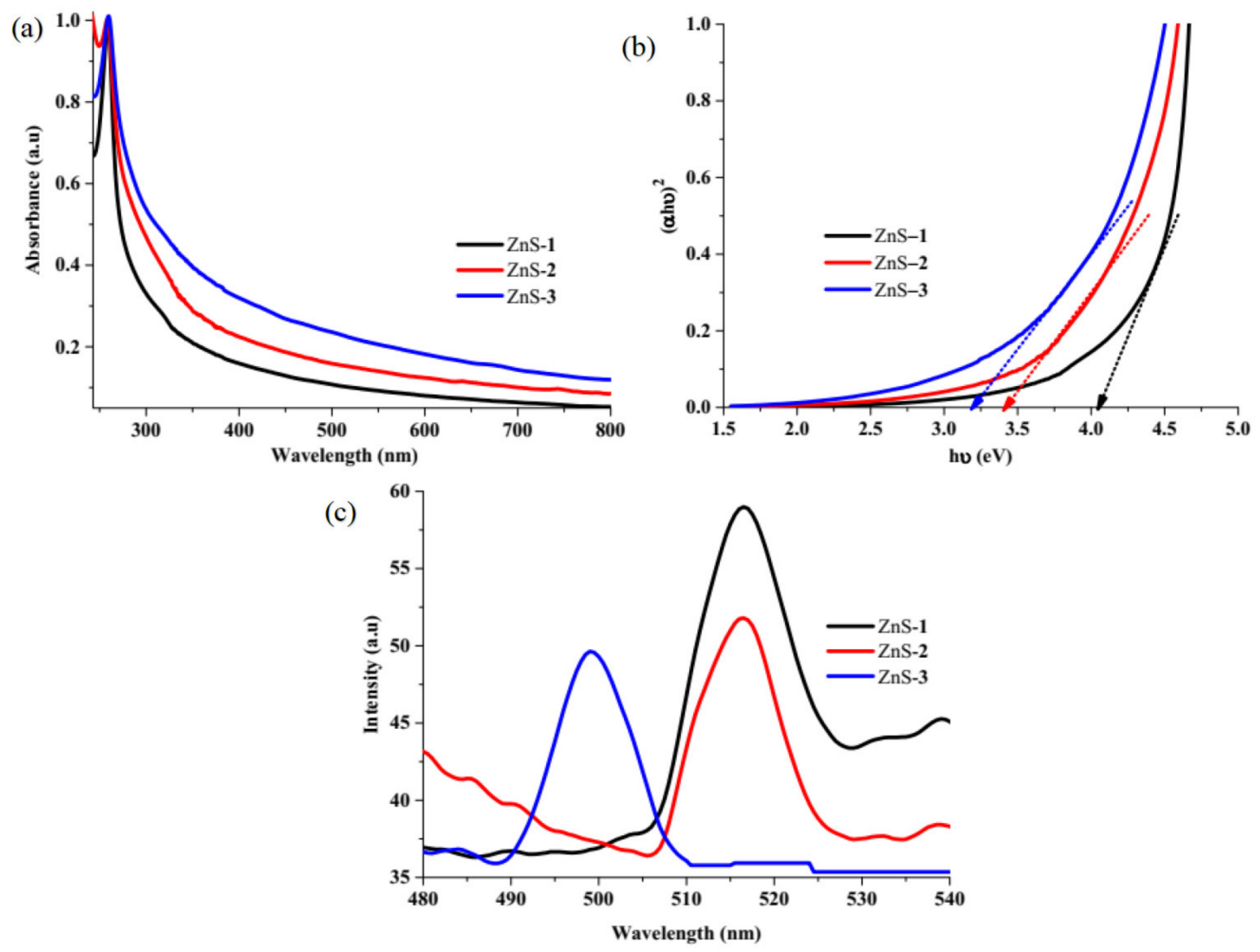

Figure 3. ZnS quantum dots absorption spectra (a), Tauc plots (b), and photoluminescence spectra (c).

2.3. Photodegradation of Brilliant Green and Rhodamine B Dyes by the ZnS Quantum Dots 2.3.1. Effect of Catalytic Dosage on Photocatalytic Degradation

In order to determine the optimum catalytic dosage of the $\mathrm{ZnS}$ photo catalyst for optimum photocatalytic degradation, the amount of $\mathrm{ZnS}$ quantum dots catalyst was varied from $0.2 \mathrm{mg} \mathrm{L}^{-1}$ to $1.2 \mathrm{mg} \mathrm{L}^{-1}$, while the concentration of brilliant green (BG) dye was kept constant at 5 ppm, as shown in Figure 4. The photocatalytic degradation efficiencies of BG and rate over $\mathrm{ZnS}-1$ increased from $41.57 \%\left(0.0032 \mathrm{~min}^{-1}\right)$ for $0.2 \mathrm{mg} \mathrm{L}^{-1}$ to $71.61 \%\left(0.0071 \mathrm{~min}^{-1}\right)$ for $1 \mathrm{mg} \mathrm{L}^{-1}$ after which it decreased slightly. This indicates that the increase in catalytic dosage results in higher degradation efficiency, which could be ascribed to the availability of active sites on the catalyst surface, which increases the generation of $\cdot \mathrm{OH}^{-}$and $\cdot \mathrm{O}_{2}{ }^{-}$radicals [50]. However, an increase in the catalyst dosage above $1 \mathrm{mg} \mathrm{L}^{-1}$ resulted in a decrease in photodegradation efficiency to $60.37 \%\left(0.0051 \mathrm{~min}^{-1}\right)$ This could be ascribed to the scattering of light and the screening effect on the photocatalyst surface [51,52]. The results show that $1 \mathrm{mg} \mathrm{L}^{-1}$ is the optimal dosage for the photocatalytic degradation of the dyes. 

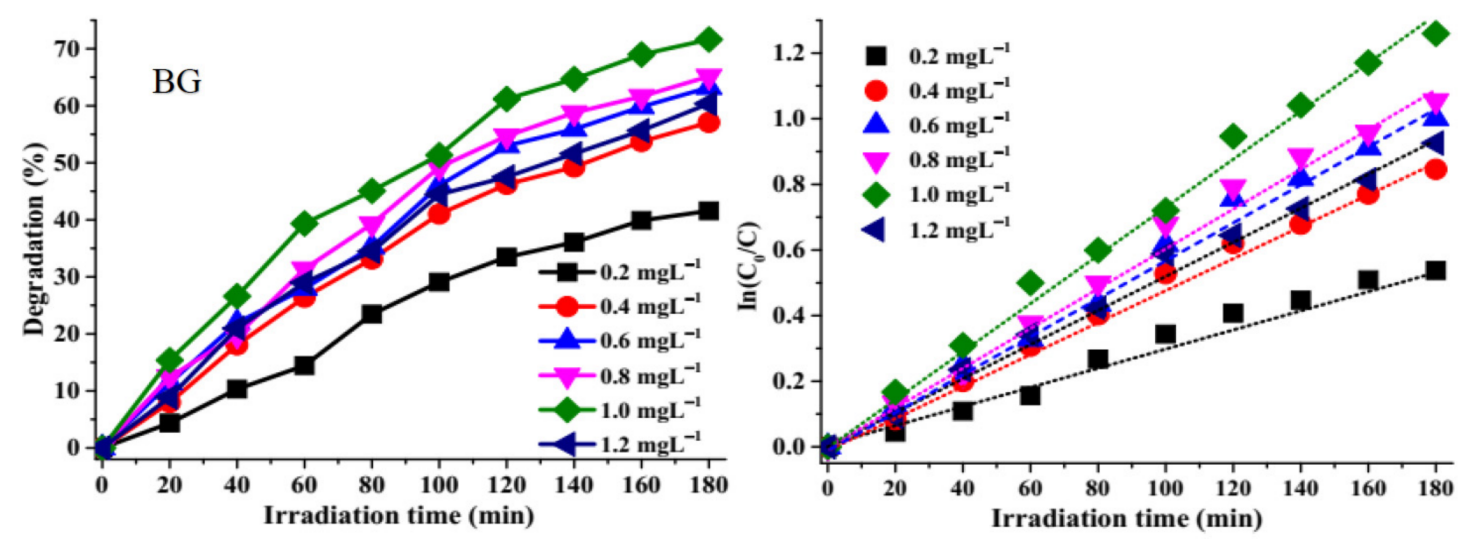

Figure 4. Effect of catalyst dosage on brilliant green over ZnS-1 and corresponding $\operatorname{In}\left(C_{0} / C\right)$ versus time plots.

\subsubsection{Effect of Irradiation Time on Photocatalytic Degradation}

The photocatalytic degradation potential of the as-synthesized ZnS quantum dots were studied against brilliant green (BG) and rhodamine B (RhB) (singles dyes), and mixtures of both dyes (binary dye (BG-RhB)) in a solution (Figure S5). The photodegradation efficiencies of BG are $71.62 \%$ by ZnS-1, $91.06 \%$ by ZnS-2, and $94.61 \%$ by ZnS-3 after $180 \mathrm{~min}$, while the photo degradation efficiencies of RhB cationic dye are $45.12 \%$ by ZnS-1, $56.69 \%$ by ZnS- 2 and $71.46 \%$ by ZnS-3. The low degradation efficiencies of RhB by the as-prepared $\mathrm{ZnS}$ quantum dots could be attributed to its complex structure. The highest degradation efficiency was obtained from ZnS-3 (Figure 5), which could be attributed to its small particle size and high rate of electron-hole pair separation efficiency, as observed in its photoluminescence spectra. While ZnS-1 and ZnS-2's lower degradation efficiency could be attributed to their high rate of electron-hole pair recombination. The overall high degradation efficiency observed by the $\mathrm{ZnS}$ quantum dots could be attributed to surface defects observed in the ZnS particles.
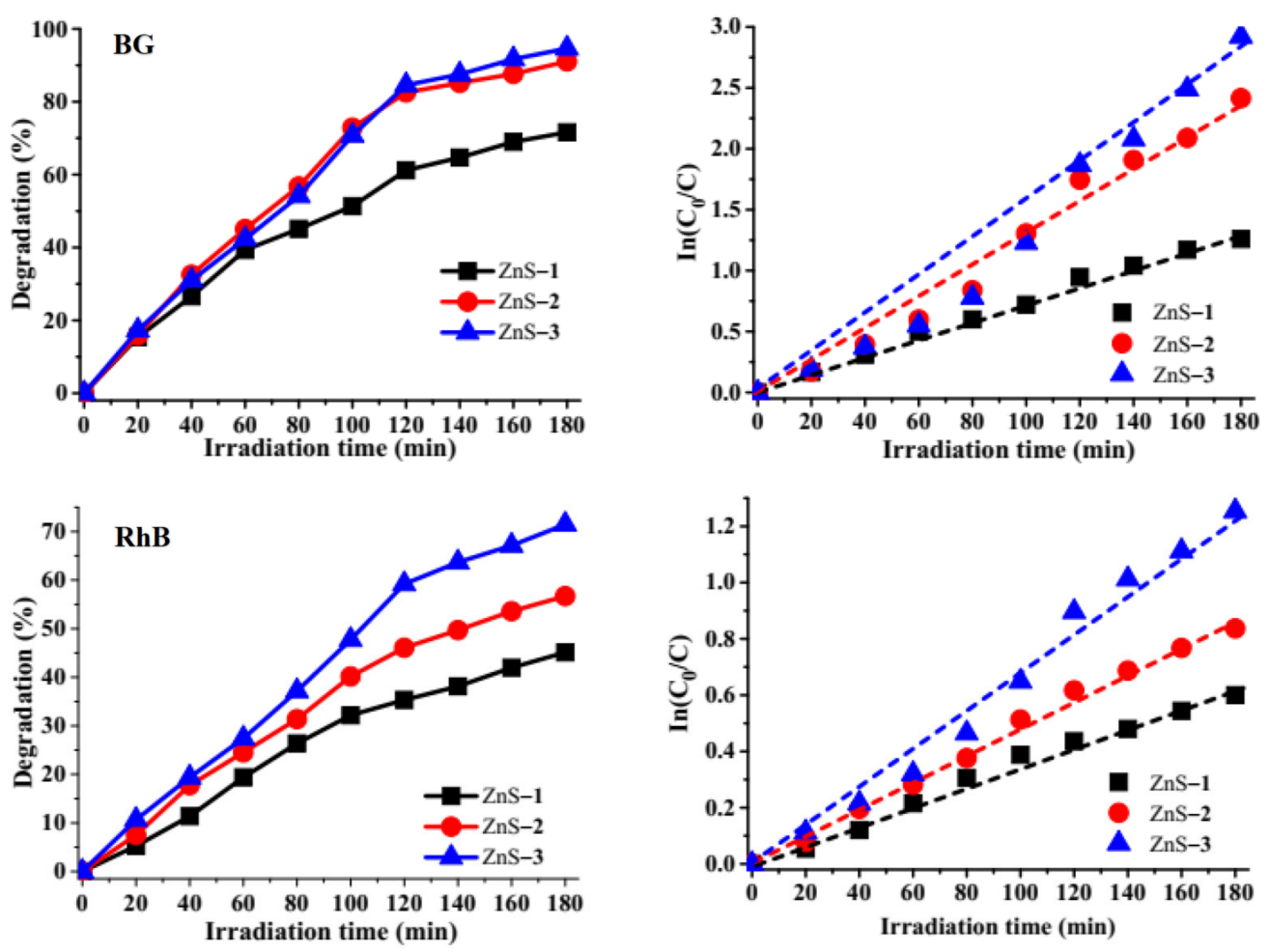

Figure 5. Degradation efficiency curves of brilliant green (BG) and rhodamine B (RhB) by ZnS quantum dots and their corresponding kinetics studies plot. 
The absorption spectra (Figure S6) of the binary-dye (BG-RhB) solution show that there is no overlap between the dyes. The absorption bands at $554 \mathrm{~nm}$ and $625 \mathrm{~nm}$ are ascribed to RhB and BG dyes, respectively. The photo degradation efficiency of BG in BG-RhB mixture is 70.60\% by ZnS-1, 88.81\% by ZnS-2, and $98.50 \%$ by ZnS-3, while the photo degradation efficiency of RhB in BG-RhB mixture was $65.81 \%$ by ZnS-1, 70.79\% by ZnS-2, and 72.71\% by ZnS-3 (Figure 6). Overall, ZnS-3 showed higher photocatalytic degradation of both the binary-dye mixture and single dyes, compared to ZnS-1 and ZnS-2.

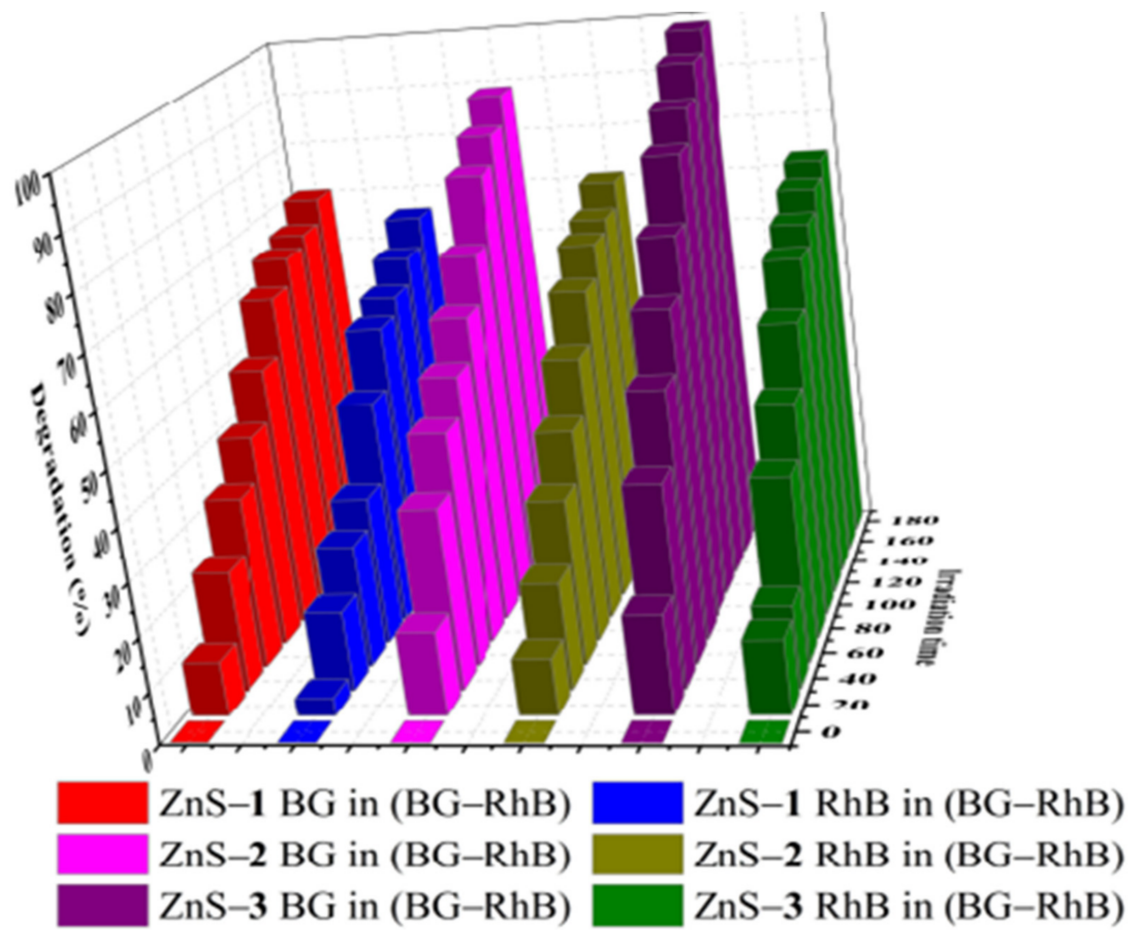

(a)

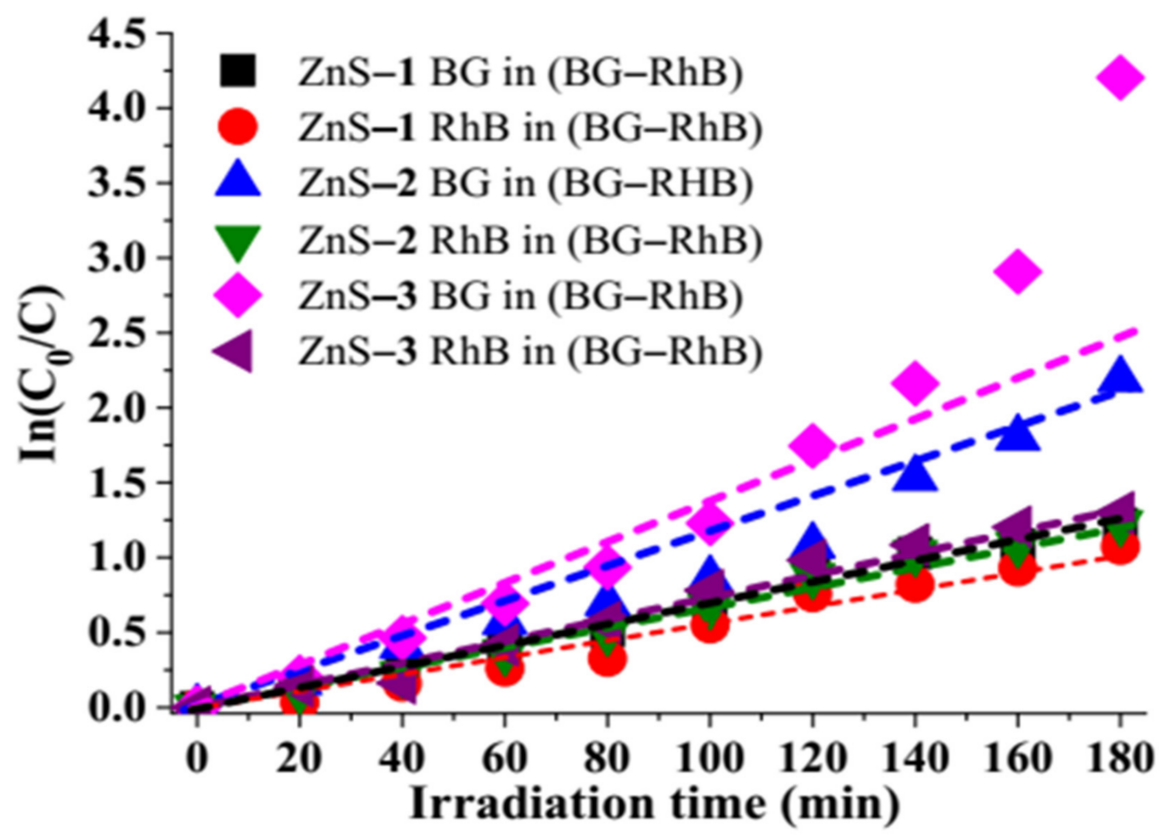

(b)

Figure 6. Degradation efficiency bar chart of binary dye by ZnS quantum dots (a), and corresponding kinetic studies plot (b). 
Analysis of the photodegradation of $\mathrm{BG}, \mathrm{RhB}$, and the binary dyes by the as-prepared $\mathrm{ZnS}$ quantum dots shows that the experiments followed pseudo-first-order kinetics due to the linear relationship between $\operatorname{In}\left(C_{0} / C\right)$ versus irradiation time, as presented in Figures 5 and 6 . Equation (1) was used to determine the rate constant ' $k$ ' of the kinetics studies $[53,54]$.

$$
\operatorname{In}\left(\frac{C_{0}}{C}\right)=k t
$$

$C_{0}$ is the initial concentration at time ' $O$ ', while $C$ is the concentration at a specific time and ' $t$ ' is the irradiation time. The extent of degradation and the corresponding rate constant and correlation coefficient are presented in Table 1.

Table 1. The photocatalytic degradation parameters of single and mixed dyes over ZnS quantum dots under visible light irradiation.

\begin{tabular}{ccccc}
\hline \multirow{2}{*}{ Dyes } & $\begin{array}{c}\text { ZnS } \\
\text { Photocatalyst }\end{array}$ & $\begin{array}{c}\text { Degradation } \\
\text { Efficiency (\%) }\end{array}$ & $\begin{array}{c}\text { Rate Constant } \boldsymbol{k} \\
\left(\mathbf{m i n}^{\mathbf{1}} \mathbf{)}\right.\end{array}$ & $\mathbf{R}^{\mathbf{2}}$ \\
\hline \multirow{3}{*}{ BG } & ZnS-1 & 71.62 & 0.0071 & 0.994 \\
& ZnS-2 & 91.06 & 0.0141 & 0.9854 \\
& ZnS-3 & 94.61 & 0.0245 & 0.9197 \\
\hline \multirow{2}{*}{ RhB } & ZnS-1 & 45.12 & 0.0034 & 0.9894 \\
& ZnS-2 & 56.69 & 0.0048 & 0.9948 \\
& ZnS-3 & 71.46 & 0.0073 & 0.9886 \\
\hline \multirow{3}{*}{ BG in (BG-RhB) } & ZnS-1 & 70.79 & 0.0061 & 0.9921 \\
& ZnS-2 & 88.81 & 0.0116 & 0.9659 \\
& ZnS-3 & 98.51 & 0.0208 & 0.9045 \\
\hline \multirow{2}{*}{ RhB in (BG-RhB) } & ZnS-1 & 65.81 & 0.0063 & 0.9818 \\
& ZnS-2 & 70.60 & 0.0072 & 0.9928 \\
& ZnS-3 & 72.71 & 0.0078 & 0.9855 \\
\hline
\end{tabular}

2.3.3. Effect of Scavengers on the Photocatalytic Degradation Efficiency of the Dyes

The photocatalytic degradation efficiency of any materials depends on the separation efficiency of electron-hole pairs $\left(\mathrm{e}^{-}-\mathrm{h}^{+}\right)$which lead to the generation of active species such as superoxide and hydroxyl radicals $\left(\cdot \mathrm{O}_{2}{ }^{-}\right.$and $\left.\cdot \mathrm{OH}^{-}\right)$through redox reactions. The photoluminescence spectra of the as-prepared $\mathrm{ZnS}$ quantum dots show defective state emission bands that promote lifetime separation of $\left(\mathrm{e}^{-}-\mathrm{h}^{+}\right)$pairs, which could enhance the photocatalytic degradation process. In order to establish which reactive species, influence the photodegradation process, isopropyl alcohol (IPA), silver nitrate (SN), and acrylamide (AC) were used as scavengers to quench $\cdot \mathrm{OH}^{-}, \mathrm{e}^{-}$, and $\cdot \mathrm{O}_{2}{ }^{-}[22,55,56]$. A comparison between the photodegradation of brilliant green, rhodamine $\mathrm{B}$, and the binary-dye solution after the addition of scavengers (Figure 7) indicates that brilliant green dye degradation efficiency by ZnS-1 decreases from 71.62\% (no scavenger) to 36.30\% (SN), 61.99\% (AC), and $67.65 \%$ (IPA) while its degradation by ZnS-2 decreases from 91.06 to $32.72 \%, 79.26 \%$, and $81.46 \%$, and with ZnS-3 it decreases from $94.61 \%$ to $50.28 \%, 84.37 \%$, and $88.59 \%$, respectively. This shows that the dominant active species are $\mathrm{e}^{-}$and $\cdot \mathrm{O}_{2}{ }^{-}$, while $\cdot \mathrm{OH}^{-}$acts as a secondary active species, which agrees with the trend observed with other catalysts $[57,58]$. However, the degradation efficiency of rhodamine B (RhB) by ZnS-1 decreases from 45.12\% (no scavenger) to $29.89 \%$ (IPA), $14.33 \%$ (SN) and $19.79 \%$ (AC) whereas with ZnS-2 the degradation efficiency decreases from 56.69 (no scavenger) to $29.06 \%$ (IPA), $16.31 \%$ (SN) and 23.45 (AC). The effect of scavengers shows that with $\mathrm{ZnS}-3$, the photocatalytic degradation efficiency decreases from $71.46 \%$ (no scavenger) to $45.56 \%$ (IPA), $25.78 \%$ (SN) and $37.97 \%$ (AC). The same trends were observed for the degradation of rhodamine $\mathrm{B}$ in the binary-dye mixture after the addition of scavengers. With the binary dyes, the addition of $\mathrm{SN}, \mathrm{AC}$, and IPA resulted in a reduction in degradation of RhB in (BG-RB) from $65.81 \%$ to $10.96 \%, 62.66 \%$, and $51.17 \%$ by $\mathrm{ZnS}-1$, while with $\mathrm{ZnS}-2$ the photocatalytic degradation 
efficiency decreased from $70.79 \%$ to $14.42 \%, 48.87 \%$, and $51.29 \%$, and with ZnS-3 the photocatalytic degradation efficiency decreased from $72.71 \%$ to $30.20 \%, 56.82 \%$, and $59.64 \%$. However, for brilliant green dye in the mixed dyes, the degradation efficiency decreased from $70.60 \%$ to $14.32 \%, 64.94 \%$ and $54.56 \%$ by ZnS-1, while with ZnS-2 it decreased from $88.80 \%$ to $24.91 \%, 53.23 \%$, and $70.79 \%$, and by ZnS-3 the degradation efficiency decreased from $98.51 \%$ to $36.37 \%, 84.32 \%$, and $90.81 \%$, respectively. The results indicate that $\cdot \mathrm{O}_{2}{ }^{-}$ and $\mathrm{e}^{-}$play significant roles in the degradation of rhodamine $\mathrm{B}$ compared to $\cdot \mathrm{OH}^{-}$, which agrees with previous reports using other photocatalysts [22,59].
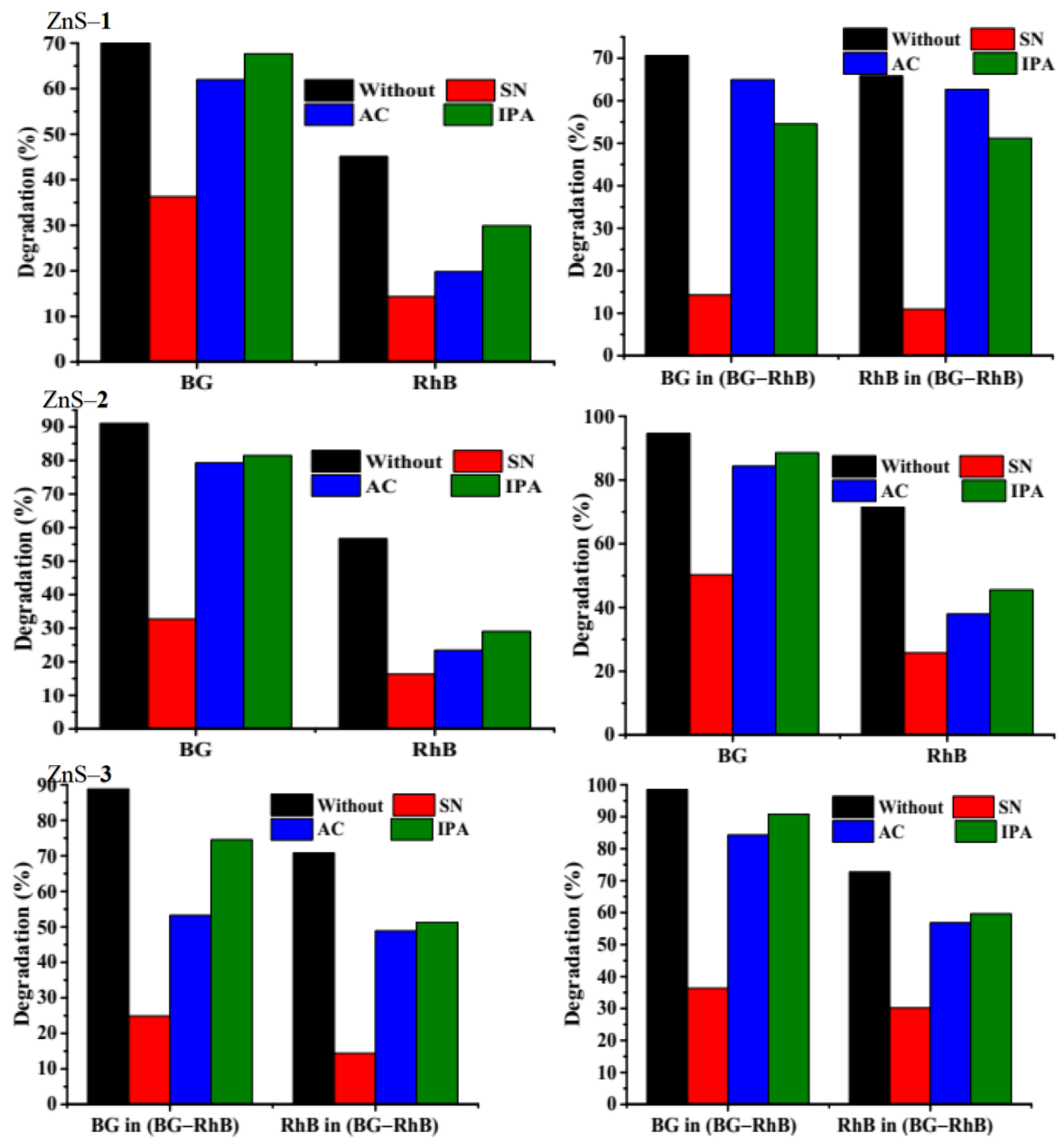

Figure 7. Effect of scavengers on single and binary dyes over ZnS quantum dots photocatalyst.

\subsubsection{Photostability Studies of the ZnS Quantum Dots}

Photostability is an important attribute of photocatalysts. Hence, recyclability experiments were carried out to determine the stability of the as-synthesized ZnS. Figure 8 shows that the photodecomposition rates of brilliant green, rhodamine $\mathrm{B}$, and binary dyes were significantly stable until the fifth cycles, which demonstrates excellent stability and reusability. After each run, the $\mathrm{ZnS}$ photocatalyst was washed by centrifugation and reused in the subsequent run. The reduction by the fifth cycle could be attributed to either accumulation of the by-products on the particles' surface or the loss of particles during the filtration process, washing, and agglomeration of the catalyst as the number of cycles increases during the experiment $[22,60]$. 

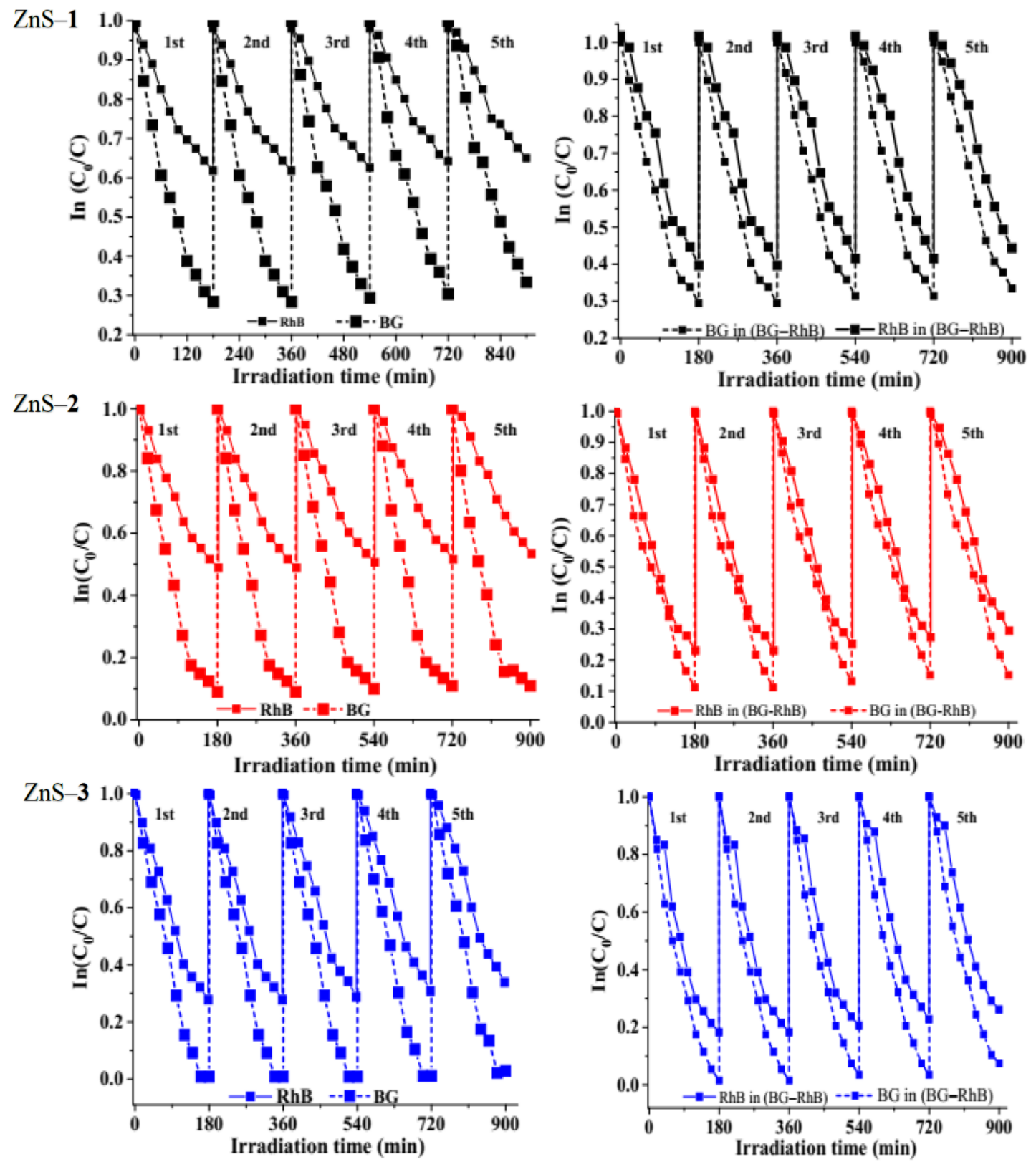

Figure 8. Reusability test of as-prepared ZnS catalysts on brilliant green (BG), rhodamine b (RhB), and binary dyes.

\subsubsection{Effect of $\mathrm{pH}$ on Photocatalytic Degradation}

It is important to evaluate the photocatalytic efficiency at different $\mathrm{pH}$, as it is an important factor in changing the catalyst's surface charge and the organic dye. It was observed that there was a sudden disappearance in color of brilliant green dye at $\mathrm{pH} 10$, which could be due to the disruption of the alternate double- and single-conjugated bonds in brilliant green [61].

It has been reported that at $\mathrm{pH} 10$, the brilliant green dye becomes electrophilic, thereby becoming unstable and colorless [25], hence $\mathrm{pH} 8$ was set as the maximum $\mathrm{pH}$. Three different $\mathrm{pH}(3,6.5$, and 8$)$ of the dye solution were used to evaluate the degradation efficiency at a constant catalytic dosage $(5 \mathrm{mg})$ and dye concentration (5 ppm) for BG, RhB, and BG-RhB dye solutions (Figure 9). The degradation efficiency of the brilliant green solution by the $\mathrm{ZnS}$ quantum dots was at the lower $\mathrm{pH} 3$ (40.57\% for ZnS-1, 45.43\% for ZnS-2, and $52.11 \%$ for ZnS-3), while at the higher $\mathrm{pH}$ 8, the degradation rate increased to 76.85\% for ZnS-1, 97.64\% for ZnS-2, and 99.29\% for ZnS-3. The increase in the degradation 
efficiency could be attributed to the increase in availability of hydroxyl groups, making the degradation process favorable in alkaline media [57]. Furthermore, the degradation of rhodamine $\mathrm{B}$ using the same $\mathrm{pH}$ resulted in a different trend from brilliant green. At $\mathrm{pH} 3$, the degradation efficiency of rhodamine B decreased to $21.35 \%$ for ZnS-1, 31.52\% for ZnS-2, and $36.39 \%$ for $\mathrm{ZnS}-3$. This could be attributed to the generation of $\mathrm{Zn}^{2+}$, which results in a reduced concentration of protons in the solution [62]. While at $\mathrm{pH} 8$, the photocatalytic degradation efficiency increased to $29.60 \%$ for ZnS-1, $44.48 \%$ for ZnS-2, and $49.08 \%$ for $\mathrm{ZnS}-3$. This could be due to the formation of rhodamine B zwitterion [63]. At $\mathrm{pH}$ higher than 8 , rhodamine $\mathrm{B}$ has been reported to degrade poorly due to a high $\mathrm{OH}^{-}$concentration which reacts with $\cdot \mathrm{OH}$, reducing the availability of the active species [51]. The same trend was observed with the photocatalytic degradation of the binary dye. The mechanism of the brilliant green and rhodamine B is similar to other studies where tin sulfide and copper sulfide nanoparticles were used as photocatalysts [31,59].
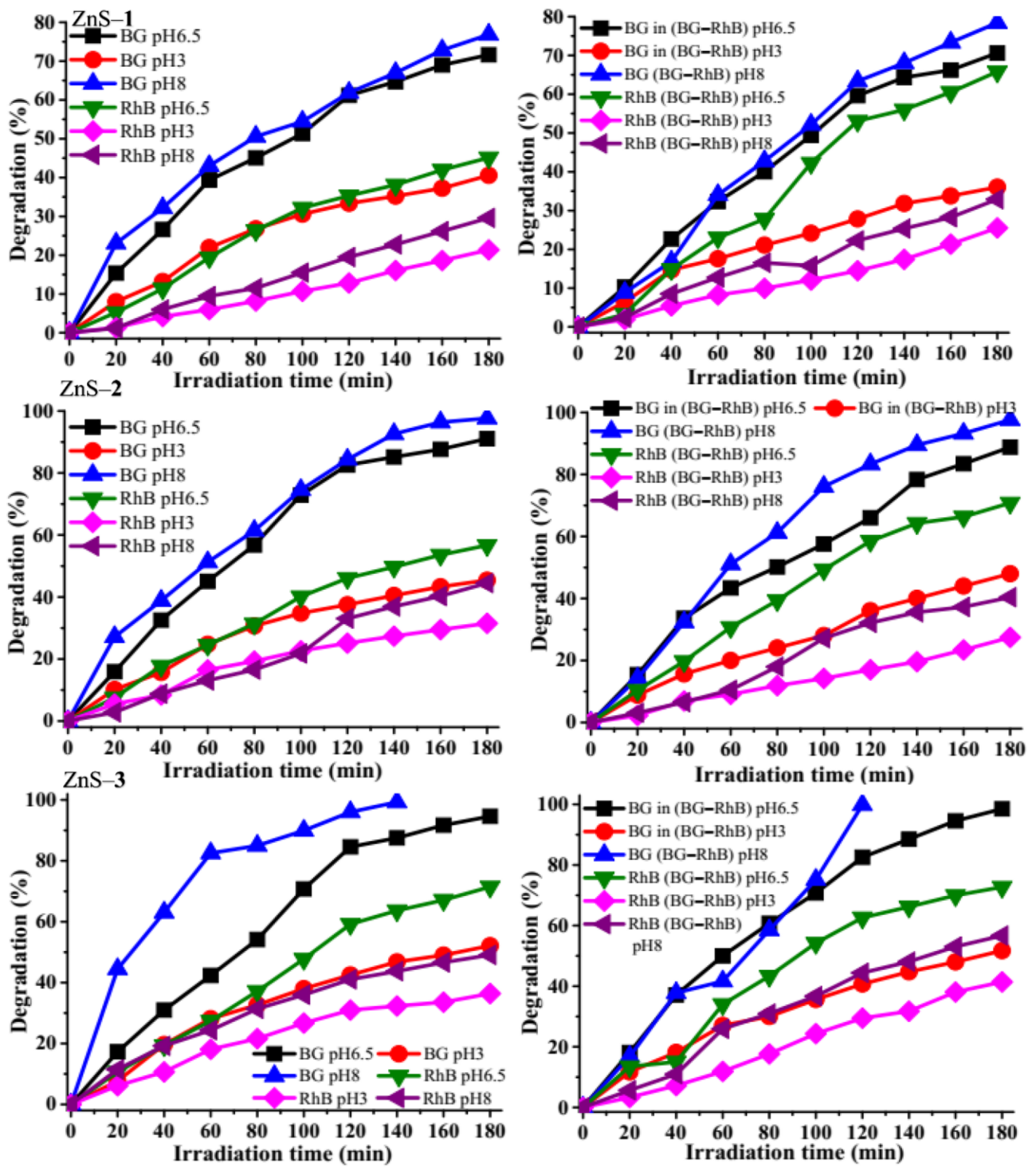

Figure 9. Effect of $\mathrm{pH}$ on brilliant green (BG), rhodamine $\mathrm{B}(\mathrm{RhB})$, and binary dyes over $\mathrm{ZnS}$ quantum dots.

\section{Materials and Methods}

\subsection{Materials}

Oleic acid $(99 \%)$, octadecylamine $(90 \%)$, methanol $(\geq 99.9 \%)$, toluene $(\geq 99.5 \%)$, brilliant green $(\sim 90.0 \%)$, rhodamine B $(95 \%)$, silver nitrate $(\geq 99.0 \%)$, acrylamide $(98 \%)$, and isopropanol were purchased from Merck (Darmstadt, Germany). All reagents were used 
as obtained without further purification. Bis(morpholinyldithiocarbamato) $\mathrm{Zn}$ (II) complex was prepared using reported procedure [64].

\subsection{Physical Characterization Techniques}

Powder X-ray diffraction (XRD, Bruker D8 (Billerica, MA, USA) Cu-K $\alpha$ irradiation $\lambda=1.5405 \AA$ ) was used for phase identification of the $\mathrm{ZnS}$ quantum dots. The surface morphology and elemental composition of the $\mathrm{ZnS}$ quantum dots were recorded with scanning electron microscope (ZEISS FEGSEM, Oberkochen, Germany) equipped with electron diffraction spectroscopy at $20 \mathrm{kV}$ rating voltage. High-resolution transmission electron microscope (HRTEM, JEOL-2100 (Akishima, Tokyo, Japan)) was used to determine the particle size and shapes of the as-prepared ZnS nanoparticles. Agilent Cary 630 spectrometer (Santa Clara, CA, USA) was used to take FTIR spectra of the ZnS nanoparticles. PerkinElmer Lambda 25 UV-Vis spectrophotometer (Waltham, MA, USA) and PerkinElmer LS 45 fluorescence spectrometer (Waltham, MA, USA) were used to measure absorption spectra and photoluminescence, respectively.

\subsection{Synthesis of ZnS Quantum Dots}

Bis(morpholinyldithiocarbamato)Zn(II) complex $(0.5 \mathrm{~g})$ was dissolved in $15 \mathrm{~mL}$ of oleic acid; the suspension obtained was injected into octadecylamine $(6 \mathrm{~g})$ at $130^{\circ} \mathrm{C}$. A decrease in temperature to $117{ }^{\circ} \mathrm{C}$ was observed. The temperature was stabilized at $130{ }^{\circ} \mathrm{C}$ and maintained for $30 \mathrm{~min}$ under nitrogen flow while stirring. Afterward, the reaction mixture was cooled to $70{ }^{\circ} \mathrm{C}$, and excess methanol was added to precipitate the nanoparticles. The nanoparticles were isolated by centrifugation at $5000 \mathrm{rpm}$ for $30 \mathrm{~min}$. The resulting solid was dried at room temperature and labeled ZnS-1. The complex was thermolyzed for $1 \mathrm{~h}$ to prepare $\mathrm{ZnS}-2$, while thermolysis of the complex for $2 \mathrm{~h}$ resulted in zinc sulfide quantum dot labeled as ZnS-3.

\subsection{Photocatalytic Studies of the ZnS Quantum Dots}

The photocatalytic degradation efficiency of the $\mathrm{ZnS}$ quantum dots were evaluated through the photodegradation of brilliant green, rhodamine $B$ and mixture of brilliant green-rhodamine B (binary dye) solution. Before irradiation, the $\mathrm{ZnS}$ quantum dots and the dye solution were stirred magnetically for $30 \mathrm{~min}$ under dark conditions to establish an adsorption-desorption equilibrium between dyes and photocatalyst surface. The study was carried out in vials under visible light irradiation. For the photo degradation experiment, $5 \mathrm{~mL}$ of brilliant green dye solution ( $5 \mathrm{ppm}$ concentration) was treated with the different quantum dots $(5 \mathrm{mg})$ in seven vials placed in circular metal support exposed to high pressure sodium lamp OSRAM VIALOX $(80 \mathrm{~W})$. A control experiment with ZnS quantum-dot-catalyst-free brilliant green solution was also carried out to monitor the photo degradation of the dyes. At regular time intervals $(20 \mathrm{~min})$, a sample vial was taken out and the concentration of the dye was measured by recording the UV absorbance in the range of 200-800 nm, using a UV-visible spectrophotometer.

The degradation efficiency was calculated from Equation (2) [65]:

$$
\text { Efficiency }(\%)=\frac{C_{0}-C}{C_{0}} \times 100
$$

where $C_{0}$ and $C$ are the dye concentrations before and after photoirradiation, respectively.

$\mathrm{ZnS}$ quantum dots' stability and reusability during the photocatalytic process were assessed with the same visible light irradiation and after each degradation cycle. The ZnS quantum dots' photocatalyst was separated by filtration and washed many times with distilled water, and then photodegradation of the dyes was carried out under the same conditions. 


\subsection{Detection of Reactive Oxygen Species Test}

The detection of reactive species is an essential theme in photocatalytic degradation process. Different scavengers such as isopropyl alcohol (IPA), acrylamide (AC), or silver nitrate (SN) were used as quenching agents of $\mathrm{h}^{+}, \mathrm{e}^{-}$and $\mathrm{OH}^{-}$, respectively. Each scavenger was added into the brilliant green aqueous solution prior to the addition of $\mathrm{ZnS}$ quantum dots as photo catalysts. The exact process as mentioned earlier was repeated for aqueous rhodamine B and binary-dye solution [55].

\section{Conclusions}

Bis(morpholinyldithiocarbamato)Zn(II) complex was thermolyzed at $130{ }^{\circ} \mathrm{C}$ in octadecylamine at $30 \mathrm{~min}$ to prepared $\mathrm{ZnS}-\mathbf{1}$, at $1 \mathrm{~h}$ to prepared $\mathrm{ZnS}-\mathbf{2}$, and at $2 \mathrm{~h}$ to prepared ZnS-3 quantum dots. The degradation of brilliant green, rhodamine $B$, and binary dye (mixture of brilliant green-rhodamine B) were used to evaluate the potential of the asprepared zinc sulfide quantum dots as photocatalysts. Powder X-ray diffraction patterns confirmed the $\mathrm{ZnS}$ hexagonal wurtzite phase, and the diffraction peaks became sharper as the thermolysis time increased. HRTEM micrographs revealed spherically shaped particles with sizes of $1.3 \mathrm{~nm}$ for ZnS-1 prepared at $30 \mathrm{~min}, 1.08-3.42 \mathrm{~nm}$ for ZnS-2 prepared at $1 \mathrm{~h}$, and $0.80-2.88 \mathrm{~nm}$ for ZnS-3 prepared at $2 \mathrm{~h}$. The energy band gap of the zinc sulfide quantum dots estimated from the Tauc plots were $4.09 \mathrm{eV}$ for ZnS-1, $3.46 \mathrm{eV}$ for ZnS-2, and $3.17 \mathrm{eV}$ for ZnS-3. The energy band gaps were blue-shifted, which could be ascribed to quantum confinement effect as a result of the small particle size of the as-prepared $\mathrm{ZnS}$ quantum dots. The $\mathrm{ZnS}$ quantum dots were used as photocatalysts for the degradation of brilliant green (BG), rhodamine $B(\mathrm{RhB})$, and a mixture of brilliant green and rhodamine B binary dyes (BG-RhB). Photocatalytic degradation efficiencies of $71.61 \%$ (ZnS-1), 91.06\% (ZnS-2), and 94.61\% (ZnS-3) were obtained for BG, while degradation efficiencies of $45.12 \%$ (ZnS-1), 56.69\% (ZnS-2), and 71.46\% (ZnS-3) were obtained for RhB. However, the degradation efficiency of BG in the binary-dye mixture (BG-RhB) by ZnS-1 was $70.60 \%, 88.80 \%$ by $\mathrm{ZnS}-2$, and $98.51 \%$ by ZnS-3, while the degradation efficiency of $\mathrm{RhB}$ in the ternary dye mixture (BG-RhB) was $65.81 \%$ by $\mathrm{ZnS}-1,70.79 \%$ by $\mathrm{ZnS}-2$, and $72.71 \%$ by ZnS-3. The studies show that degradation efficiency increases with an increase in catalytic dosage up to $1 \mathrm{mg} \mathrm{mL}^{-1}$ of the $\mathrm{ZnS}$ nano-photocatalyst, while alkaline medium is more favorable for photocatalytic degradation. The most dominant active species in the photodegradation of the dyes were electron holes, super oxides, and hydroxyl radicals. The reusability studies of the $\mathrm{ZnS}$ quantum dots indicate that they are stable and recyclable even after five catalytic cycles.

Supplementary Materials: The following are available online. Figure S1: Particle size distributions of the $\mathrm{ZnS}$ nanoparticles, Figure S2: Powder X-ray diffraction patterns of ZnS quantum dots prepared at $30 \mathrm{~min}$ (ZnS-1), $1 \mathrm{~h}$ (ZnS-2) and $2 \mathrm{~h}$ (ZnS-3), Figure S3: SEM images of the ZnS quantum dots, Figure S4: EDX spectra of the ZnS quantum dots, Figure S5: Absorption spectra of brilliant green $(\mathrm{a}-\mathrm{c})$ and rhodamine B $(\mathrm{d}-\mathrm{f})$ over $\mathrm{ZnS}$ quantum dots, Figure S6: Absorption spectra of BG-RhB degradation over $\mathrm{ZnS}$ quantum dots.

Author Contributions: Conceptualization, P.A.A.; supervision, data acquisition and analysis, funding acquisition, writing-review, and final editing. A.E.O. Data acquisitions, data analysis, and writing - draft. All authors have read and agreed to the published version of the manuscript.

Funding: This research received no external funding.

Acknowledgments: The authors appreciate SASOL and the National Research Foundation (NRF) for financial support.

Conflicts of Interest: The authors declare no conflict of interest. 


\section{References}

1. Sabzehmeidani, M.M.; Karimi, H.; Ghaedi, M. Electrospinning preparation of NiO/ZnO composite nanofibers for photodegradation of binary mixture of rhodamine B and methylene blue in aqueous solution: Central composite optimization. Appl. Organomet. Chem. 2018, 32, e4335. [CrossRef]

2. Liu, H.; Guo, W.; Li, Y.; He, S.; He, C. Photocatalytic degradation of sixteen organic dyes by $\mathrm{TiO}_{2} / \mathrm{WO}_{3}$-coated magnetic nanoparticles under simulated visible light and solar light. J. Environ. Chem. Eng. 2018, 6, 59-67. [CrossRef]

3. Wang, W.; Lu, T.; Chen, Y.; Tian, G.; Sharma, V.K.; Zhu, Y.; Zong, L.; Wang, A. Mesoporous silicate/carbon composites derived from dye-loaded palygorskite clay waste for efficient removal of organic contaminants. Sci. Total Environ. 2019, 696, 133955. [CrossRef] [PubMed]

4. Wang, Y.; Pan, Y.; Zhu, T.; Wang, A.; Lu, Y.; Lv, L.; Zhang, K.; Li, Z. Enhanced performance, and microbial community analysis of bioelectrochemical system integrated with bio-contact oxidation reactor for treatment of wastewater containing azo dye. Sci. Total Environ. 2018, 634, 616-627. [CrossRef]

5. Guo, K.; Gao, B.; Tian, X.; Yue, Q.; Zhang, P.; Shen, X.; Xu, X. Synthesis of polyaluminium chloride/papermaking sludge-based organic polymer composites for removal of disperse yellow and reactive blue by flocculation. Chemosphere 2019, 231, 337-348. [CrossRef] [PubMed]

6. Amanulla, B.; Sannasi, S.; Abubakker, A.K.M.; Ramaraj, S.K. A magnetically recoverable bimetallic Au-FeNPs decorated on g- $\mathrm{C}_{3} \mathrm{~N}_{4}$ for efficient photocatalytic degradation of organic contaminants. J. Mol. Liq. 2018, 249, 754-763. [CrossRef]

7. Aziz, A.; Ali, N.; Khan, A.; Bilal, M.; Malik, S.; Ali, N.; Khan, H. Chitosan-zinc sulfide nanoparticles, characterization and their photocatalytic degradation efficiency for azo dyes. Int. J. Biol. Macromol. 2020, 153, 502-512. [CrossRef] [PubMed]

8. López-Vinent, N.; Cruz-Alcalde, A.; Romero, L.; Chávez, M.; Marco, P.; Giménez, J.; Esplugas, S. Synergies, radiation and kinetics in photo-Fenton process with UVA-LEDs. J. Hazard. Mater. 2019, 380, 120882. [CrossRef]

9. Dias, N.C.; Bassin, J.P.; Sant'Anna, G.L., Jr.; Dezotti, M. Ozonation of the dye reactive red 239 and biodegradation of ozonation products in a moving-bed biofilm reactor: Revealing reaction products and degradation pathways. Int. Biodeterior. Biodegrad. 2019, 144, 104742. [CrossRef]

10. Innocenzi, V.; Prisciandaro, M.; Centofanti, M.; Vegliò, F. Comparison of performances of hydrodynamic cavitation in combined treatments based on hybrid induced advanced fenton process for degradation of azo-dyes. J. Environ. Chem. Eng. 2019, 7, 103171. [CrossRef]

11. Barrocas, B.; Entradas, T.; Nunes, C.; Monteiro, O. Titanate nanofibers sensitized with ZnS and $\mathrm{Ag}_{2} \mathrm{~S}$ nanoparticles as novel photocatalysts for phenol removal. Appl. Catal. B Environ. 2017, 218, 709-720. [CrossRef]

12. Yan, Y.; Yang, M.; Wang, C.; Liu, E.; Hu, X.; Fan, J. Defected ZnS/bulk g- $\mathrm{C}_{3} \mathrm{~N}_{4}$ heterojunction with enhanced photocatalytic activity for dyes oxidation and Cr(VI) reduction. Colloids Surf. A Physicochem. Eng. Asp. 2019, 582, 123861. [CrossRef]

13. Xiao, J.-H.; Huang, W.-Q.; Hu, Y.-S.; Zeng, F.; Huang, Q.-Y.; Zhou, B.-X.; Pan, A.; Li, K.; Huang, G.-F. Facile in situ synthesis of wurtzite $\mathrm{ZnS} / \mathrm{ZnO}$ core/shell heterostructure with highly efficient visible-light photocatalytic activity and photostability. J. Phys. D Appl. Phys. 2018, 51, 075501. [CrossRef]

14. Liu, Y.; Shen, S.; Zhang, J.; Zhong, W.; Huang, X. $\mathrm{Cu}_{2-x} \mathrm{Se} / \mathrm{CdS}$ composite photocatalyst with enhanced visible light photocatalysis activity. Appl. Surf. Sci. 2019, 478, 762-769. [CrossRef]

15. Raza, W.; Ahmad, K. ZnO nanostructures for photocatalytic dye degradation under visible light irradiation. In Environmental Nanotechnology for Water Purification; Scrivener Publ. LLC: Beverly, MA, USA, 2020; pp. 259-284.

16. Jiang, Y.; Weiss, E.A. Colloidal quantum dots as photocatalysts for triplet excited state reactions of organic molecules. J. Am. Chem. Soc. 2020, 142, 15219-15229. [CrossRef] [PubMed]

17. Que, Q.; Xing, Y.; He, Z.; Yang, Y.; Yin, X.; Que, W. $\mathrm{Bi}_{2} \mathrm{O}_{3} /$ Carbon quantum dots heterostructured photocatalysts with enhanced photocatalytic activity. Mater. Lett. 2017, 209, 220-223. [CrossRef]

18. Liang, Y.; Ma, H.; Zhang, W.; Cui, Z.; Fu, P.; Liu, M.; Qiao, X.; Pang, X. Size effect of semiconductor quantum dots as photocatalysts for PET-RAFT polymerization. Polym. Chem. 2020, 11, 4961-4967. [CrossRef]

19. Wang, Y.; Li, Y.; Zhao, J.; Wang, J.; Li, Z. g- $\mathrm{C}_{3} \mathrm{~N}_{4}$ / B doped g- $\mathrm{C}_{3} \mathrm{~N}_{4}$ quantum dots heterojunction photocatalysts for hydrogen evolution under visible light. Int. J. Hydrogen Energy 2019, 44, 618-628. [CrossRef]

20. Zeng, Z.; Chen, S.; Tan, T.T.Y.; Xiao, F.-X. Graphene quantum dots (GQDs) and its derivatives for multifarious photocatalysis and photoelectrocatalysis. Catal. Today 2018, 315, 171-183. [CrossRef]

21. Mansur, A.A.; Mansur, H.S.; Ramanery, F.P.; Oliveira, L.C.; Souza, P.P. “Green” colloidal ZnS quantum dots/chitosan nanophotocatalysts for advanced oxidation processes: Study of the photodegradation of organic dye pollutants. Appl. Catal. B Environ. 2014, 158, 269-279. [CrossRef]

22. Samanta, D.; Basnet, P.; Chanu, T.I.; Chatterjee, S. Biomolecule assisted morphology-controllable synthesis of zinc sulphide nanomaterials for efficient photocatalytic activity under solar irradiation. J. Alloys Compd. 2020, 844, 155810. [CrossRef]

23. Xiao, X.; Ma, X.-B.; Yuan, H.; Liu, P.-C.; Lei, Y.-B.; Xu, H.; Du, D.-L.; Sun, J.-F.; Feng, Y.-J. Photocatalytic properties of zinc sulfide nanocrystals biofabricated by metal-reducing bacterium Shewanella oneidensis MR-1. J. Hazard. Mater. 2015, 288, 134-139. [CrossRef]

24. Osuntokun, J.; Ajibade, P.A.; Onwudiwe, D.C. Synthesis and photocatalytic studies of ZnS nanoparticles from heteroleptic complex of Zn (II) 1-cyano-1-carboethoxy-2, -2-ethylenedithiolato diisopropylthiourea and its adducts with N-donor ligands. Superlattices Microstruct. 2016, 100, 605-618. [CrossRef] 
25. Kaur, S.; Sharma, S.; Umar, A.; Singh, S.; Mehta, S.; Kansal, S.K. Solar light driven enhanced photocatalytic degradation of brilliant green dye based on ZnS quantum dots. Superlattices Microstruct. 2017, 103, 365-375.

26. Li, Y.-X.; Fu, H.; Wang, P.; Zhao, C.; Liu, W.; Wang, C.-C. Porous tube-like ZnS derived from rod-like ZIF-L for photocatalytic Cr (VI) reduction and organic pollutants degradation. Environ. Pollut. 2020, 256, 113417. [CrossRef]

27. Jacob, J.M.; Rajan, R.; Tom, T.C.; Kumar, V.S.; Kurup, G.G.; Shanmuganathan, R.; Pugazhendhi, A. Biogenic design of ZnS quantum dots-Insights into their in-vitro cytotoxicity, photocatalysis and biosensing properties. Ceram. Int. 2019, 45, 24193-24201. [CrossRef]

28. Selvaganapathi, P.; Thirumaran, S.; Ciattini, S. Structural variations in zinc (II) complexes with N, N-di (4-fluorobenzyl) dithiocarbamate and imines: New precursor for zinc sulfide nanoparticles. Polyhedron 2018, 149, 54-65. [CrossRef]

29. Kashinath, L.; Namratha, K.; Byrappa, K. Sol-gel assisted hydrothermal synthesis and characterization of hybrid ZnS-RGO nanocomposite for efficient photodegradation of dyes. J. Alloys Compd. 2017, 695, 799-809. [CrossRef]

30. Ghorai, S.; Patra, N.; Pal, A.; Bhattacharyya, D.; Jha, S.N.; Ray, B.; Chatterjee, S.; Ghosh, A.K. Insights into local atomic structure of Fe alloyed ZnS nano crystals: Correlation with structural, optical, magnetic and photocatalyst properties. J. Alloys Compd. 2019, 805, 363-378. [CrossRef]

31. Oluwalana, A.E.; Ajibade, P.A. Tin sulfide nanoparticles as photocatalysts for the degradation of organic dyes. J. Sulfur Chem. 2021, 1-22. [CrossRef]

32. Paca, A.M.; Ajibade, P.A. Synthesis and structural studies of iron sulphide nanocomposites from iron (III) dithiocarbamate single source precursors. Mater. Chem. Phys. 2017, 202, 143-150. [CrossRef]

33. Ajibade, P.A.; Botha, N.L. Synthesis and structural studies of copper sulfide nanocrystals. Res. Phys 2016, 6, 581-589. [CrossRef]

34. Ajibade, P.A.; Oluwalana, A.E.; Sikakane, B.M.; Singh, M. Structural, photocatalytic and anticancer studies of hexadecylamine capped ZnS nanoparticles. Chem. Phys. Lett. 2020, 755, 137813. [CrossRef]

35. Liu, S.; Li, H.; Yan, L. Synthesis and photocatalytic activity of three-dimensional ZnS/CdS composites. Mater. Res. Bull. 2013, 48, 3328-3334. [CrossRef]

36. Entradas, T.; Cabrita, J.; Barrocas, B.; Nunes, M.; Silvestre, A.J.; Monteiro, O. Synthesis of titanate nanofibers co-sensitized with $\mathrm{ZnS}$ and $\mathrm{Bi}_{2} \mathrm{~S}_{3}$ nanocrystallites and their application on pollutants removal. Mater. Res. Bull. 2015, 72, 20-28. [CrossRef]

37. Cao, X.-Q.; Wang, X.; Chen, M.; Xiao, F.; Huang, Y.-M.; Lyu, X.-J. Synthesis of nanoscale zeolitic imidazolate framework-8 (ZIF-8) using reverse micro-emulsion for congo red adsorption. Sep. Purif. Technol. 2021, 260, 118062. [CrossRef]

38. Sun, J.Q.; Shen, X.P.; Chen, K.M.; Liu, Q.; Liu, W. Low-temperature synthesis of hexagonal ZnS nanoparticles by a facile microwave-assisted single-source method. Solid State Commun. 2008, 147, 501-504. [CrossRef]

39. Hosseinzadeh, G.; Maghari, A.; Farniya, S.M.F.; Keihan, A.H.; Moosavi-Movahedi, A.A. Interaction of insulin with colloidal ZnS quantum dots functionalized by various surface capping agents. Mater. Sci. Eng. C 2017, 77, 836-845. [CrossRef]

40. Sharma, J.; Gupta, A.; Pandey, O. Effect of Zr doping and aging on optical and photocatalytic properties of ZnS nanopowder. Ceram. Int. 2019, 45, 13671-13678. [CrossRef]

41. Sabaghi, V.; Davar, F.; Fereshteh, Z. ZnS nanoparticles prepared via simple reflux and hydrothermal method: Optical and photocatalytic properties. Ceram. Int. 2018, 44, 7545-7556. [CrossRef]

42. Ummartyotin, S.; Bunnak, N.; Juntaro, J.; Sain, M.; Manuspiya, H. Synthesis and luminescence properties of ZnS and metal (Mn, Cu)-doped-ZnS ceramic powder. Solid State Sci. 2012, 14, 299-304. [CrossRef]

43. Green, M. The nature of quantum dot capping ligands. J. Mater. Chem. 2010, 20, 5797-5809. [CrossRef]

44. Abha, K.; Sumithra, I.; Suji, S.; Anjana, R.; Devi, J.A.; Nebu, J.; Lekha, G.; Aparna, R.; George, S. Dopamine-induced photoluminescence quenching of bovine serum albumin-capped manganese-doped zinc sulphide quantum dots. Anal. Bioanal. Chem. 2020, 412, 5671-5681. [CrossRef] [PubMed]

45. Hanifehpour, Y.; Soltani, B.; Amani-Ghadim, A.R.; Hedayati, B.; Khomami, B.; Joo, S.W. Synthesis and character-ization of samarium-doped ZnS nanoparticles: A novel visible light responsive photocatalyst. Mater. Res. Bull. 2016, 76, 411-421. [CrossRef]

46. Dumbrava, A.; Berger, D.; Prodan, G.; Matei, C.; Moscalu, F.; Diacon, A. The influence of triton X-100 surfactant on the morphology and properties of zinc sulfide nanoparticles for applications in azo dyes degradation. Mater. Chem. Phys. 2017, 193, 316-328. [CrossRef]

47. Wang, C.; Ao, Y.; Wang, P.; Zhang, S.; Qian, J.; Hou, J. A simple method for large-scale preparation of ZnS nano-ribbon film and its photocatalytic activity for dye degradation. Appl. Surf. Sci. 2010, 256, 4125-4128. [CrossRef]

48. Prasannalakshmi, P.; Shanmugam, N. Fabrication of $\mathrm{TiO}_{2} / \mathrm{ZnS}$ nanocomposites for solar energy mediated photocatalytic application. Spectrochim. Acta A Mol. Biomol. Spectrosc. 2017, 175, 1-10. [CrossRef]

49. Wang, G.; Huang, B.; Li, Z.; Lou, Z.; Wang, Z.; Dai, Y.; Whangbo, M.-H. Synthesis and characterization of ZnS with controlled amount of $\mathrm{S}$ vacancies for photocatalytic $\mathrm{H}_{2}$ production under visible light. Sci. Rep. 2015, 5, 8544. [CrossRef]

50. Ajibade, P.A.; Oluwalana, A.E.; Andrew, F.P. Morphological studies, photocatalytic activity, and electrochemis-try of platinum disulfide nanoparticles from Bis(morpholinyl-4-carbodithioato)-platinum (II). ACS Omega 2020, 5, 27142-27153. [CrossRef] [PubMed]

51. Ahmad, M.; Rehman, W.; Khan, M.M.; Qureshi, M.T.; Gul, A.; Haq, S.; Ullah, R.; Rab, A.; Menaa, F. Phytogenic fabrication of ZnO and gold decorated $\mathrm{ZnO}$ nanoparticles for photocatalytic degradation of rhodamine B. J. Environ. Chem. Eng. 2021, 9, 104725. [CrossRef] 
52. Kumar, T.M.P.K.; Kumar, S.K.A. Visible-light-induced degradation of rhodamine B by nanosized $\mathrm{Ag}_{2} \mathrm{~S}-\mathrm{ZnS}$ loaded on cellulose. Photochem. Photobiol. Sci. 2019, 18, 148-154. [CrossRef]

53. Kaur, J.; Gupta, A.; Pandey, O. Photocatalytic study of ZnS-Ag2S nanocomposites-effect of thioglycerol. Sol. Energy 2018, 176, 678-687. [CrossRef]

54. Jothibas, M.; Manoharan, C.; Jeyakumar, S.J.; Praveen, P.; Punithavathy, I.K.; Richard, J.P. Synthesis and enhanced photocatalytic property of Ni doped ZnS nanoparticles. Sol. Energy 2018, 159, 434-443. [CrossRef]

55. Palanisamy, G.; Bhuvaneswari, K.; Chinnadurai, A.; Bharathi, G.; Pazhanivel, T. Magnetically recoverable multifunctional $\mathrm{ZnS} / \mathrm{Ag} / \mathrm{CoFe}_{2} \mathrm{O}_{4}$ nanocomposite for sunlight driven photocatalytic dye degradation and bactericidal application. J. Phys. Chem. Solids 2020, 138, 109231. [CrossRef]

56. Guo, M.; Song, M.; Li, S.; Yin, Z.; Song, X.; Bu, Y. Facile and economical synthesis of ZnS nanotubes and their superior adsorption performance for organic dyes. Cryst. Eng. Comm. 2017, 19, 2380-2393. [CrossRef]

57. Sree, G.S.; Botsa, S.M.; Reddy, B.J.M.; Ranjitha, K.V.B. Enhanced UV-Visible triggered photocatalytic degradation of brilliant green by reduced graphene oxide based $\mathrm{NiO}$ and $\mathrm{CuO}$ ternary nanocomposite and their antimicrobial activity. Arab. J. Chem. 2020, 13, 5137-5150. [CrossRef]

58. Mishra, S.; Sahu, T.K.; Verma, P.; Kumar, P.; Samanta, S.K. Microwave-assisted catalytic degradation of brilliant green by spinel zinc ferrite sheets. ACS Omega 2019, 4, 10411-10418. [CrossRef]

59. Ajibade, P.A.; Oluwalana, A.E. Enhanced photocatalytic degradation of ternary dyes by copper sulfide nanoparticles. Nanomaterials 2021, 11, 2000. [CrossRef] [PubMed]

60. Tie, L.; Sun, R.; Jiang, H.; Liu, Y.; Xia, Y.; Li, Y.-Y.; Chen, H.; Yu, C.; Dong, S.; Sun, J. Facile fabrication of N-doped ZnS nanomaterials for efficient photocatalytic performance of organic pollutant removal and $\mathrm{H}_{2}$ production. J. Alloys Compd. 2019, 807, 151670. [CrossRef]

61. Rao, C.V.; Giri, A.S.; Goud, V.V.; Golder, A.K. Studies on pH-dependent color variation and decomposition mechanism of brilliant green dye in Fenton reaction. Int. J. Ind. Chem. 2016, 7, 71-80. [CrossRef]

62. Le, A.T.; Samsuddin, N.S.B.; Chiam, S.-L.; Pung, S.-Y. Synergistic effect of $\mathrm{pH}$ solution and photocorrosion of ZnO particles on the photocatalytic degradation of rhodamine B. Bull. Mater. Sci. 2021, 44, 5. [CrossRef]

63. Hariprasad, N.; Anju, S.; Yesodharan, E. Sunlight induced removal of rhodamine B from water through semi-conductor photocatalysis: Effects of adsorption, reaction conditions and additives. Res. J. Mater. Sci. 2013, 2320, 6055.

64. Ajibade, P.A.; Andrew, F.P.; Botha, N.L.; Solomane, N. Synthesis, crystal structures and anticancer studies of morpholinyldithiocarbamato $\mathrm{Cu}(\mathrm{II})$ and $\mathrm{Zn}(\mathrm{II})$ complexes. Molecules 2020, 25, 3584. [CrossRef] [PubMed]

65. Oluwalana, A.E.; Ajibade, P.A. Structural, optical and photocatalytic studies of hexadecylamine-capped lead sulfide nanoparticles. Int. J. Ind. Chem. 2020, 11, 249-260. [CrossRef] 